\title{
Interface of the Reader with the Text: From Individual to Group Transactions for Meaning
}

\author{
Dr. Reid Allen S. Ugsang* \\ Principal, National Christian Life College
}

\author{
*Corresponding Author: Dr. Reid Allen S. Ugsang, Principal, National Christian Life College
}

\begin{abstract}
The recent development in the educational system in the Philippines brought challenges to the educators and policymakers all over the country. The instruction, design, and implementation brought defy learners' comprehension and general understanding in which most cases influenced by the teachers' relative approaches and perspectives. This study is a qualitative investigation of the grade 10 learners who interfaced as readers with the text which were classified into individual and group construction for meaning. Subsequently, the researcher cited Boeije (2002) Step-by-Step Constant Comparison and endeavored to polish the same by appropriating the steps involved. The findings propose that here is a weighty truth on how the grade 10 readers have the ability to interface through individual and group's responses of the chosen piece entitled, Chopin's Story of an Hour with the revelation of the occurrence of meaning destabilization. During this study's reader-text interface process, there are several different ways in which the text can be read, thus making the point that meaning is consistently provisional, always ready to pave a way to other meaning, hence, taking note the factors that if not addressed, may greatly influence adverse impact in the overall understanding of the learners.
\end{abstract}

Keywords: Interface, Authorial, Crossed Meaning, Meaning Destabilization, Transaction

\section{INTRODUCTION}

Today, education is facing great challenges due to the recent change in the Philippine Educational System - K to 12 Basic Education Program, which was signed into law in 2013 for immediate implementation by President BenignoS. Aquino III. Its immediacy is an urgent response to be at par with international standards. This initiative is hoped to realize the country's commitment to achieving the goals of Education for All (EFA), which is a UNESCO declaration. Thus, the Philippine government recognizes the new distinctive feature of the K12 curriculum, which is likewise the guiding principle emanating from the idea of learner-centeredness that gives prime importance to the development of learners' self-propelling intercultural communication skills for independent lifelong survival.

The instruction becomes the implementation's centerpiece that strikesevery teacher who is currently interfacing with many new ways of thinking and either imply a positive or negative impact the diverse population of target learners' with unique needs and aspirations from the more traditional cohorts of the past.

The part of the K-12 Program is designed to improve the curriculum toprepare the learner's ability in both oral communications and thinking skills aswell as their capabilities in performing learning tasks for better understanding of the real world. The reading comprehension and mathematical abilities are only few of the main concentrations which were given priority by the Philippine Department of Education (DepEd). It is very important that in the K12 Program, the students will benefit with emphasis on the preparation for their collegial life after two years extension of the Senior High School. With the advent of technology, it is much easier in dealing with the learners using their different capabilities especially in reading and analyzing selections assigned by the teachers.

In order to prepare students for a broad range of employmentopportunities, Philippine basic education schools must focus developing as desired outcomes these 'graduate attributes' or 'essential learning outcomes' in addition to content knowledge and disciplinary expertise (Oliver, 2015).

While lists of graduate attributes may vary, certain skills are invariablylisted, including communication skills (Institute for Teaching and Learning, 2015). The ability to communicate has 
been consistently identified by employers as one of the essential attributes of graduates in this curriculum.

Accordingly, there is no more important educational outcome than thelearners' ability to communicate, which an essential skill for access in a globally-intercultural setting. However, the learners' intercultural communication success largely depends on its prerequisite - reading comprehension. Hence, the teacher should understand that different learners have a different understanding of a particular written or oral discourse.

In most cases, a learner's understanding may be different from what areading teacher thinks about or considers. If these conflicting perspectives are to be considered; then, the validity and dependability of the information shared between the learners and the teachers may likewise spell out confusing meanings when the process of communication happens with other readers. In normal circumstances, a teacher cannot practically reach out to each and every learner as required; and therefore, the reading study design must allow different learners to get involved in the reader-text engagement process.

\subsection{Statement of the Problem}

Practically in this study, this reader-text process is conceived to be aqualitative exploration of the grade 10 learners who interfaced as readers with the text. Such interfacing begun from individual meaning construction to social or group construction for meaning.

Because this researcher is very much interested in discovering what meanings learners of Grade 10 will provide when asked to interface certain literary text types individually and collectively, the researcher has consequently advanced the following questions as a guide to his exploration:

- What meaning classification can be derived from readers' individual andgroup transactions as a result of their interfacing with the given text?

- What thematic categorization can be derived from the readers' meaningclassification?

- What conceptual framework can emerge from the transacted, constructed,classified, and categorized meanings?

- What theoretical and/or practical explanations can be given to thetransacted, constructed, classified, categorized meanings by review validation?

\section{REVIEW OF RELATED LiTERATURE}

\subsection{Teaching Strategies vs. Learning Achievements}

When proficient readers get confused or off track, they realize this rightaway then consciously shift mental gears and apply appropriate strategies. Theymight identify the source of the confusion, reread it, and then explain it to themselves. They might knowingly make connections to fill in what the author leaves unsaid. And they might record important ideas and information, form sensory images, or ask themselves questions. Adolescent readers benefit from robust, general strategies that can be applied to a range of situations (Alexander \& Jetton, 2000).

Along with having a repertoire of general strategies, proficient readers know how to adjust these strategies according to the particular texts and tasks at hand. For instance, readers continually make inferences to comprehend texts, but the specific types of inference vary (RAND Reading Study Group, 2002). When reading imaginative fiction, readers make inferences to interpret characters' motivations; when reading scientific exposition, readers make inferences to link technical details.

For the purpose of this study, this section presented seven generalstrategies known to promote adolescents' reading comprehension. The strategies are ones that proficient readers use regularly and across a wide variety of texts:

\subsection{Reading Comprehension Strategies}

There are various strategies in achieving reading comprehension of the students. The first step is (1) Plan and Monitor which involves controlling one's mental activities; it is metacognitive in nature, centering about readers' awareness and control of their comprehension. When engaged with this strategy, youth are taught planning skills - how to preview texts and how to set a purpose for reading and make predictions. They are also taught how to clarify ideas by using fix-up strategies and how to clarify vocabulary by using context clues and other word level fix-up strategies. 
Second is (2) Determine Importance which includes the identification ofidentifying essential ideas and information. This is the ability to separate the wheat from the chaff in text. Youth are taught how to identify stated and implied main ideas, how to summarize texts, and how to note the personal relevance of ideas and information.

Next is to (3) Ask Questions which this stage involves interrogating textsfor a variety of purposes, such as checking one's understanding, querying the author about his or her writing, and discerning relationships among ideas and information within a text

Next is to (4) Make Inferences which is often known as "reading betweenthe lines," includes linking parts of texts that authors did not link explicitly. Using what one already knows to form links across sentences and paragraphs.

The fifth step is to (5) Make Connections. This includes using what isknown to enrich the authors' meanings; taking what has been learned from one's own life experiences, other texts, and cultural and global matters to deepen understandings of what the author presents. The step following connection making is (6) Synthesize by which this phase of putting together ideas from multiple sources; deciding how ideas go together in a way that is new; figuring out on how reading and learning fit together in a way not thought as before.

Youth are taught how to draw conclusions, form generalizations, and make comparisons across texts.

Finally, the last step is to (6) Visualize. This is the period forming sensoryand emotional images of textual contents, especially visual images. This strategy also includes an aspect specifically for teens who don't consider themselves to be readers: the strategy of recognizing that one is having an emotional response while reading and identifying what the author did to invoke that response. This set of seven is based on the reading comprehension strategy research that has been reviewed at length since the early 1990s (Gersten, Fuchs, Williams \&Baker, 2001; National Reading Panel, 2000) and especially the research that embraces adolescents (Alvermann, Fitzgerald, \& Simpson, 2006).

There is a striking agreement that low-achieving adolescent readersimprove their comprehension performance when they learn to apply strategies. This improvement has been demonstrated among adolescent native English speakers as well as adolescent English language learners who struggle with reading (Short \& Fitzsimmons, 2007).

\subsection{Structuralism for Text-Dependent Theories for Meaning Construction}

In a structuralist studies, activities are as diverse such as in food preparation and serving rituals, religious rites, games, literary and non-literary texts, and other forms of entertainment to discover the deep structures by which meaning is produced and reproduced within a culture. When used to examine literature, a structuralist critic will examine the underlying relation of elements, the 'structure' in, say, a story, rather than focusing on its content (Klages, 2005).

The relations among signs are of two sorts, contiguity and substitutability, the axes of combination and selection: hence the existence of all 'grammars', hence all substitutions, hence the ability to know something by something else or by a part of it in some way -- hence metonymy and metaphor. The conception of combination and selection provides the basis for an analysis of 'literariness' or 'poeticality' in the use, repetition and variation of sound patterns and combinations. It also provides keys to the most fundamental elements of culture.

One point to cite is binarism or dualism which is the ontological division of a domain into two discrete categories (dichotomies) or polarities. The concept of binarism is a more loaded term which critics have applied to what they regard as the obsessive dualism of structuralists such as Lévi-Strauss and Jakobson(Klages, 2005). The binary oppositions or digital oppositions include the pairs of mutually-exclusive signifiers in a paradigm set representing categories which arelogically opposed and which together define a complete universe of discourse which are relevant ontological domains. In such oppositions, each term necessarily implies the opposite and there is no middle term. Structuralism notes that much of our imaginative world is structured of, and structured by, binary opposition like being/nothingness, hot/cold, or culture/nature and one can describe as fields of cultural thought, or topoi, by describing the binary sets which compose them.

Structuralism forms the basis for semiotics, the study of signs: a sign is aunion of signifier and signified, and is anything that stands for anything else. Central too to semiotics is the idea of codes, which give signs context like cultural codes, literary codes, and others. 
The study of semiotics and of codes opens up literary study to cultural study, and expands the resources of the critic in discussing the meaning of texts. The idea of structuralism is a study of the cultural construction or identification of meaning according to the relations of signs that constitute the meaning-spectrum of the culture. Some signs carry with them larger cultural meanings, usually very general; these are called, by Roland Barthes, "myths", or second-order signifiers. Structuralism introduces the idea of the 'subject', as opposed to the idea of the individual, a stable indivisible ego.

\subsection{Post-Structuralism for Deconstruction to understand Reader-Dependent Theories for Meaning Construction}

Post-structuralism refers to the intellectual developments in continental philosophy and critical theory that were outcomes of twentieth-century French philosophy. The prefix "post" refers to the fact that many contributors such as Jacques Derrida, Michel Foucault, and Julia Kristeva were former structuralistswho, after abandoning structuralism, became quite critical of it. In direct contrast to structuralism's claims of culturally independent meaning, post structuraliststypically view culture as inseparable from meaning.

While post-structuralism is difficult to define or summarize, it can bebroadly understood as a body of distinct reactions to structuralism. There are two main reasons for this difficulty. First, it rejects definitions that claim to have discovered absolute 'truths' or facts about the world. Second, very few people have willingly accepted the label 'post-structuralist'; rather, they have been labeled as such by others.

Therefore no one has felt compelled to construct a 'manifesto' of poststructuralism. The exact nature of post-structuralism and whether it can be considered a single philosophical movement is debated. It has been pointed out that the term is not widely used in Europe (where most supposedly "poststructuralist" theory originates) and that the concept of a post-structuralisttheoretical paradigm is largely the invention of American academics and publishers. Post-structural practices generally operate on some basic assumptions. Post-structuralists hold that the concept of "self" as a singular and coherent entity is a fictional construct. Instead, an individual comprises conflicting tensions and knowledge claims such as gender, class, and profession.

Therefore, to properly study a text a reader must understand how the work is related to his or her own personal concept of self. This self-perception plays a critical role in one's interpretation of meaning. While different thinkers' views on the self or the subject vary, it is often said to be constituted by discourse(s). Lacan's account includes a psychoanalytic dimension, while Foucault stresses the effects of power on the self.

In his essay "Signification and Sense," Emmanuel Lévinas remarked on this new field of semantic inquiry:

"Language refers to the position of the listener and the speaker, that is, to the contingency of their story. To seize by inventory all the contexts of language and all possible positions of interlocutors is a senseless task. Every verbal signification lies at the confluence of countless semantic rivers. Experience, like language, no longer seems to be made of isolated elements lodged somehow in a Euclidean space... [Words] signify from the "world" and from the position of one who is looking."

\section{RESEARCH DESIGN}

This study is a qualitative inquiry that dominantly followed the conventions of the Constant Comparative Method (CCM) developed by Glaser and Strauss (Glaser and Strauss, 1967; Strauss, 1987; Glaser, 1992). Comparison is the dominant principle of the analysis process in all the traditions of qualitative research. However, it is to note that all the kinds of aids, such as memo writing, close reading and rereading, coding, displays, data matrices and diagrams support the principle of comparison followed the thematic interpretation of data.

\subsection{The Principle of Constant Comparison}

The constant comparison approach by Glaser and Strauss (1967) developed a theoretical or conceptual framework which aims to provide explanation on how the social work operates. Glaser and Strauss (1967) further posited that when used to generate theory, the comparative analytical 
method they describe can be applied to social units of any size. The method of comparing and contrasting is used for practically all intellectual tasks during analysis: forming categories, establishing the boundaries of the categories, assigning the segments to categories, summarizing the content of each category, and finding negative evidence. The goal is to discern conceptual similarities, to refine the discriminative power of categories, and to discover patterns. This process continues until a strong theoretical understanding of an event, object,setting or phenomenon has emerged.

By comparing, the researcher is able to do what is necessary to develop aframework more or less inductively, namely categorizing, coding, delineating categories and connecting them. Constant comparison goes hand-in-hand with theoretical sampling. This principle implies that the researcher decides what data will be gathered next and where to find them on the basis of provisionary theoretical ideas. In this way, it is possible to answer questions that have arisen from the analysis of and reflection on previous data. Such questions concern interpretations of phenomena as well as boundaries of categories, assigning segments or finding relations between categories. The data in hand are then analyzed again and compared with the new data. The units should be chosen with great care and in a way that enables questions, new or otherwise, to be answered efficiently and effectively, thereby allowing the process of analysis and in particular the comparative process to progress.

\subsection{The Step-by-Step Constant Comparison}

According to Strauss and Corbin (1998), the art of comparison has to do with creative processes and with the interplay between data and researcher when gathering and analyzing data. Beside 'close-in' comparisons that serve the more traditional functions mentioned above, they distinguish so-called 'far-out' comparisons.

Despite pointing out the aim of CCM, the application of the methods andtechniques remains rather unclear. There is more to this process than just comparing everything that crosses the researcher's path. The lack of clear-cut questions and a prior coding system means that data have to be produced by the researcher in the course of the study. It is necessary to understand the 'production' procedure, which takes place primarily at the data analysis stage, in order to judge the value of a study.

\subsection{Research Instruments}

The research instruments were the Meaning Transaction Task Sheets that were originally constructed by the researcher and were validated by five experts in the field of teaching reading.

To establish construct and face validity, the task sheets were pilot-testedin two reading classes in the grade 9 with the use of another literary text. The instruments have the following two major categories:

- The Individual Meaning Transaction Task Sheet (Think-Alone Interfacing Task Sheet) is a learner tool that can capture individuallearner's specific meaning construction from the given literary text.

- The "Pair-Share" Interfacing Task Sheet is the next tool used tocapture construction of meanings from the same texts with other learners in a social-learning circle and tried to derive general meanings.

- The Individual and Group Meaning Task Sheet for the same short story were illustrated in Appendix C \& D.

\subsection{Data-Gathering Procedure}

In order to understand the study, the following procedures were being observed;

- Considering the Individual and Group Meaning Task Sheets, gathering their point of views on the reading selections as stated;

- Selecting of the readings being explored by the writer which was stated in the study and will be subjected for the verification with the respondents.

- Rewriting and evaluating the data coming from the respondents' subject for evaluation and interpretation with the literary analysis on how they understand those selections being presented in the study. 
The researcher used Qualitative Data Analysis (QDA) which consisted ofthree parts: 1) noticing, 2) collecting, and 3) thinking about interesting things. QDA is generally a non-liner process and often can be recursive. In the process of collecting information, the researcher noticed new things and thought about them. As a result, the researcher sometimes needed to go back to old data and analyze them again. In general, noticing means taking notes based on gathering documents and the like. In the analysis phase, the researcher went through the data and often marked important sections and added descriptive name or 'code' to it. This is the first step of coding and is called open coding.

After the validation of the Individual and Group Meaning Task Sheets, anddetermining the participants of the study, the researcher secured a permit from the school's supervisor for the administration of the research tools.

The researcher held an orientation to the students which lasted for almost 30 minutes prior to the actual implementation of the study. The two sections comprised of 29 and 21 students, respectively. The questions included in the Task Sheets were crafted from the short story The Story of an Hour by Kate Chopin, a popular short story which emphasizes the idea that communication or news can be fatal. Surprising information has the power to shock; and thus, has the power to kill someone. This short story was primordially selected for two reasons:

- Its emphasis on the youth's choices and decisions, marriage andchallenges, and situational Irony and reactions appropriately conforms to the current developmental stage and interests of the grade 10 learners who are in their youthful years.

- Its brevity or conciseness requiring high analytical and critical thinkingskills perfectly jibes with the Short \& Fitzsimmons, 200 reading attention span of grade 10 readers, who may be not so much interested in reading a literary text, especially a challenging short story like Chopin's writings. Although there was a strong presence of the element of surprise as ending achieved by Chopin through the use of a plot device called situational irony or irony of expectation, the challenge on its level of readability was still addressed by its brevity that led to higher reading face validity, and its enumerated youthful themes likewise led to a higher construct reading validity.

In the course of the task sheet administration, the grade 10 readers weregiven three (3) hours with an extension of one (1) hour to accomplish the two Meaning Sheets. There were several guide questions posted after the readings which were considered being one of the essences of the activity to understand the selections which was considered as one of the manifestations in analyzing the context of the stories as stated.

\section{RESULTS AND DISCUSSION}

From the grade 10 learners who were requested to individually interface with the Chopin's The Story of an Hour, they were able to derive complementary meanings. This implied that individual readers provided responses were somewhat similar with the author's embedded meanings.

In order to provide answers to the statement of the problem, theresearcher identified the emerging patterns from the respondents and analyzed the gathered data through thematic interpretation of the results to explore and interrogate what meanings were formed by the learners of grade 10 who were asked to interface certain literary text types both individually and collectively.

\subsection{What Meaning Classification can be Derived from Readers' Individual and Social Transactions as the Result of their Interfacing with the Given Text?}

Accordingly, the derived meanings from readers' individual and group interfaced with the given text were coded into:

- Crossed (Authorial) Meaning (CA). This occurred when the researcher did not see the expected response based on the authorial meanings reflected in the learners' individual and group meaning transactions task sheets.

- Complementary (Deconstructed) Meaning (CD). This occurred when the researcher exactly saw the intended responses from the author of the text. In order to satisfy the demands of specific question number, the researcher performed the proposed procedure, at this point; 


\section{STEP 1. Comparison within an individual meaning transaction for specific meaning construction for classification.}

Table1 revealed how the fifty (50) readers responded to the meaningclassification implied in the "Story of the Hour." Following the first step of theCCM, there were fourteen (14) complementary or authorial meanings while there were ninety three (93) crossed or deconstructed meanings surfaced to the fore.

Table1. Summary of Meaning classification derived from readers' individual and Group as a Result of the "Story of an Hour by Kate Chopin" Reader-Text Interface

\begin{tabular}{|c|c|c|}
\hline \multirow{2}{*}{$\begin{array}{c}\text { Individual } \\
\text { Reader }\end{array}$} & \multicolumn{2}{|c|}{ Classification of Meaning } \\
\hline & $\begin{array}{c}\text { Complementary (Authorial) } \\
\text { Meaning }\end{array}$ & $\begin{array}{c}\text { Crossed (Deconstructed) } \\
\text { Meaning }\end{array}$ \\
\hline \multirow{3}{*}{ Reader 1} & (a) Freedom from Marriage & \\
\hline & $\begin{array}{l}\text { (b) Depression from } \\
\text { marriage problems }\end{array}$ & \\
\hline & & $\begin{array}{l}\text { 7) Life is short, and death is } \\
\text { unexpected }\end{array}$ \\
\hline Reader 9 & (f) Freedom from Marriage & 8) Sudden death from JOY \\
\hline \multirow[b]{2}{*}{ Reader 13} & (g) Freedom from marriage & \multirow[b]{2}{*}{ 14) Death from happiness } \\
\hline & $\begin{array}{l}\text { (h) Suffering from over } \\
\text { thinking }\end{array}$ & \\
\hline \multirow[t]{2}{*}{ Reader 28} & \multirow[t]{2}{*}{ (1) Aftermath of over thinking } & $\begin{array}{l}40) \text { Belief after clarity of } \\
\text { situations }\end{array}$ \\
\hline & & 41) Life goes on \\
\hline Reader 31 & $\begin{array}{l}\text { (m) Aftermath of over } \\
\text { thinking }\end{array}$ & 47) Cherishing every moment \\
\hline
\end{tabular}

The identified readers of the "Story of the Hour" by Kate Chopinspotlighted that the woman character that locked up and isolated herself in her room upon the news that her husband has already died indulged into over thinking. The grade 10 readers have suspected that she, being in suffering grief, has been into over thinking that lead to depression. On the other hand, the groups' crossed meanings revealed organizing themes portraying freedom, grief, acceptance, hope, and rationalization.

\subsection{What Thematic Categorization can be Derived from the Readers' Meaning Classification?}

The individual and group meanings that were classified either as complementary or crossed meanings in Tables 1 have led the researcher to the thematic categorization of classified meanings. At this stage, Step 2 of CCM was employed by the researcher.

Generally, the answer to the second general inquiry question was deemed affirmative. From the classification of complementary and crossed meanings, several thematic categories have surfaced to the fore.

\section{STEP 2. Comparison between individual meaning transactions for general meaning construction within the same group for thematic categorization.}

Looking into the cluster of themes allowed the researcher to identify the major themes: (1) Freedom; (2) Eventuality; (3) Irony; (4) Resolution; and (5) Judiciousness

Generally, the grade 10 readers have vividly seen and understood first thematic category that marriage has EVENTUALITIES that can unfavorably be twisted by the immanent IRONY that can lead to one's invocation of FREEDOM after JUDICIOUSNESS.

From their deeper individual responses of Chopin's short story, the grade10 readers have excavated life's Irony as shown by their crossed meanings that marriage is about (c) happiness from aloneness, (d) depression from Surprise that can the readers' belief that (n) nothing goes to one's way because it is fatethat brings a person to a certain point. These are the IRONY (Theme 3) that can likewise help the woman character in $(\mathrm{k})$ handling emotions with care as the, $(\mathrm{l}, \mathrm{m})$ aftermath of over thinking requiring JUDICIOUSNESS (Theme 5). 


\subsection{What Conceptual Framework can Emerge from the Transacted, Constructed, Classified, Categorized Meanings?}

After the readers have individually and collectively interfaced by transaction with the text, classification of meanings led the researcher to the categorization of meanings. From the categorized meanings, the researcher was able to derive a conceptual framework that showcases the Grade 10 learners' interfacing by transaction in Chopin's Story of an Hour

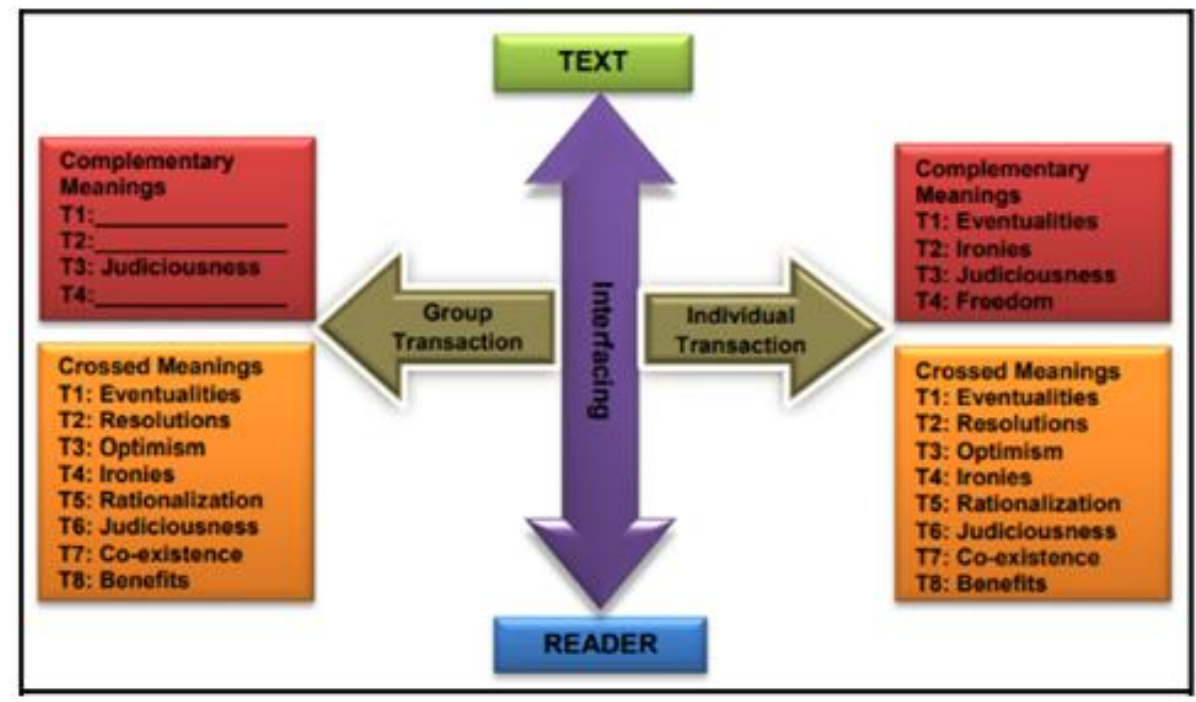

Figure1. Emerging Conceptual Framework that showcases the Grade 10 Learners' Interfacing by Transaction in Chopin's Story of an Hour

Based on the visual framework, three occurrences of meaning destabilizationcan be seen in the Individual Meaning Transaction which stars from the complementary meanings with 4 Themes to the Crossed Meanings with 8 Themes. Likewise, it is evident in the Group Meaning Transaction from Complementary meaning with only 1 Theme to the Crossed Meanings with 8 Themes. Finally, it is notable from the Individual Transaction of Complementary Meanings with 4 Themes to the Group Transaction of Complementary Meanings with only 1 Theme. However, no occurrences of meaning destabilization can be noted from the Individual Transaction of Crossed Meanings with 8 Themes to the Group

Transaction of Crossed Meanings with 8 Themes.

\subsection{What Theoretical and/or Practical Explanations can be Given to the Transacted, Constructed, Classified, Categorized Meanings by Review Validation?}

The final task of the researcher is to provide explanation to the presence and absence of meaning destabilization in the reader-text interface through the individual and group meaning transactions by the grade 10 readers. Thus, the researcher has to employ his last step which is comparison of the emerging conceptual frameworks with existing theories through review validation.

This occurrence of meaning destabilization from the reader-text interfaceby individual and group transactions of grade 10 learners can be explained by the following theories:

First, the Constructivists Learning Theory stressing a learning process that creates different meanings from various experiences (Rushby, \& Surry, 2016).Second, the constructivist's stance is further strengthened by the SchemaActivation Theory, which brings to light the impact of the learners' reading on their understanding of a particular text and on their differing backgrounds as basis of their understanding of a written text (McCormack, \& Pasquarelli, 2010).Third, the Social Cognitive Theory of Learning states that the level ofknowledge and understanding of learners is directly correlated to how they observe other people in their surroundings as well as their cognitive understanding of what's around them (Phillipson, \& Lam, 2012).Fourth, Derida's Deconstruction is actually a way of reading any text and thereby exposing the instability of meaning that the text tries to cover up.Fifth, readerresponse criticism is a school of literary theory that focuses on the reader (or "audience") and their experience of a literary work, in contrast to other schools and theories that focus attention primarily on the author or the content and form of the work. 


\section{CONCLUSION}

Generally, this study has supported that the grade 10 readers have the ability to interface through individual and group transactions with Chopin's Story of an Hour with the revelation of the occurrence of meaning destabilization. Therefore, it can be concluded that grade 10 readers have the ability to construct and deconstruct a meaning by free interface with a literary text because they possess the schema that help them unlock the meaning of a particular text with their differing backgrounds as basis of their understanding of a written text (McCormack, \& Pasquarelli, 2010).

The fundamental tenet of schema theory assumes that written text doesnot carry meaning by itself; rather, a written text only provides directions for readers as to how they should retrieve or construct meaning from their own previously acquired. It has been revealed by several studies that students learned more effectively in settings where collaboration is encouraged, and where progressive teaching methods such as discovery learning and problem solving are the focus.

Whereas a traditional critical reading attempts to establish a meaning for a text. A deconstructive reading involves asking questions in an effort to show that what the text claims to be saying and what it is really saying are different. It tries to undermine the work's implied claim of having coherence, unity, and meaning and to show that it does not represent the truth of its subject. In fact, no final statement about its meaning can be made, for each reading is provisional, just one in a series of interpretations that decenter each other in an ongoing play. In the absence of a transcendental signified, a text cannot be said to be tied to some center that existed before and outside it. Meaning can have no place to conclude, nothing in which to be subsumed.

\section{REFERENCES}

[1] Adams, M.J. \& Collins, A.M. (1979). A Schema-Theoretic View of Reading in Fredolle, R.O. (ed.) Discourse Processing. Multidisciplinary Perspectives.

[2] Anderson, R. C. (1978). Schema-Directed Processes in LanguageComprehension. Cognitive psychology and instruction. New York: Plenum.

[3] Anderson, R.C. et al. (1977). Frameworks for Comprehending Discourse. American Educational Research Journal, 14(4): 367-381

[4] Barlett, F.C. (1932). Remembering: A Study in Experimental and Social Psychology. London: New Psychological Linguistics.

[5] Berne, E. (n.d.) Transactional Analysis in Psychotherapy. Grove Press, Inc., New York, 1961. Retrieved from http://www.ericberne.com/transactionalanalysis/

[6] Boeije, H. (2002). Quality \& Quantity, 36: 391. Retrieved from https://doi.org/10.1023/A:1020909529486

[7] Carrell, P. L. et al. (1983). Interactive Approaches to second Language Reading. Cambridge: CUP.

[8] Chendan, L. (1999). Text Linguistics for Teachers. Shanghai: Shanghai Foreign Education Publication.

[9] Chundong, H. \&Cairen, W. (1998). On English Reading. Guangxi: Guangxi Education Publication.

[10] Cook, G. (2000). Professional Development and the Need for Theory. IATEFL Teacher Trainers' On Deconstruction: Theory and Criticism after Structuralism, Cornell University Press Census of Population (2015). National Capital Region (NCR). Total Population by Province, City, Municipality and Barangay. PSA. Retrieved fromhttps://en.wikipedia.org/wiki/Marikina\#Education

[11] Cruz, B., Ellerbrock, C., Vásquez, A., \& Howes, E. (2014). Talking Diversity with Teachers and Teacher Educators (1st ed.). New York: Teachers College Press.

[12] Daher, M., et al, (2017). Experience and Meaning in Qualitative Research: A Conceptual Review

[13] and a Methodological Device Proposal. Forum: Qualitative Social Research, 18(3). Retrieved from http://www.qualitativeresearch.net/index.php/fqs/article/view/2696/4129

[14] Daniels, H. (2005). Philosophy Guidebook to Derrida on Deconstruction - An Introduction to Vygotsky London: Routledge. Boston: Beacon

[15] Derrida, J., \& Spire, J. (2002). Au-del- des Apparences. Bordeaux :Éditions Le Bord de l'Eau.

[16] Derrida, J. (2005). Paper Machine. Palo Alto, CA: Stanford University Press and G. R. T. Ross. Cambridge, UK: Cambridge University Press

[17] Finch, G. (2000). Linguistic Terms and Concepts. Basingstoke-London. Macmillan Press.

[18] Glaser, B. \& Strauss, A. (1967). The Discovery of Grounded Theory: Strategies for Qualitative Research. New York: Aldine De Gruyter.

[19] Guowen, H. (1987). Essentials of Text Analysis. Hunan: Hunan Education Publication. 
[20] Harvey, M. \&Redshaw, M. (2016). Explanations and Information-Giving: Clinician Strategies Used in Talking to Parents of Preterm Infants. BMC Pediatrics, 2(11), 16:25. Retrieved from DOI: 10.1186/s12887-016-0561-6.

[21] Kameenui, E. \& Simmons, D. (1999). Toward Successful Inclusion of Students with Disabilities: The Architecture of Instruction. Retrieved from https:/www.teachervision.com/judicious-review

[22] Klages, J., Neubauer, C., Coles, M., Kessler, H. and Luy, B. (2005), Structure Refinement of Cyclosporin A in Chloroform by Using RDCs Measured in a Stretched PDMS-Gel. ChemBioChem, 6: 1672-1678. doi:10.1002/cbic. 200500146

[23] Lanir, L. (2012). Saussure - Understanding the Linguistic Value of Language

[24] Signs. Retrieved from https://www.decodedscience.org/saussureunderstanding-the-linguistic-value-oflanguage -signs/20941

[25] Leitch, V. (1980). The Lateral Dance: The Deconstructive Criticism of J. Hillis Miller. The University of Chicago Press Journals (JSTOR), 6(4), pp. 593- 607. Retrieved from http://www.jstor.org/stable/1343220

[26] Longgen, L. (1998). Cognition Frame Theory and Foreign Language Teaching. Foreign Language: 1, pp. 1-8

[27] Lycan, W. (2000). Philosophy of Language. London. Routledge.

[28] Lye, J. (2005). Some Elements of Structuralism and its Application to Literary Theory. Retrieved from http://www.brocku.ca/english/courses/4F70/struct.html

[29] McCormack, R., \& Pasquarelli, S. (2010). Teaching Reading: Strategies and Resources for Grades K-6. (1st ed.), p.94. New York: Guilford.

[30] Moore, R. (2012). Postmodernism and Punk Subculture: Cultures of Authenticity and Deconstruction. The Communication Review, 7:305-327. Retrieved from DOI: 10.1080/10714420490492238

[31] Phillips, T. (2005). The Subject of Minimalism on Aesthetics, Agency, and Becoming. Palgrave Macmillan, New York.

[32] Phillipson, S., \& Lam, B. (2012). “Learning and Teaching in the Chinese Classroom”. (1st ed.), p. 86. Hong Kong: Hong Kong University Press.

[33] Rolfe, G. (2009). The Convenient Myth of 'Good Scholarship'. Journal of Psychiatric and Mental Health Nursing, 16(4), pp:390-394. Retrieved from DOI: 10.1111/j.1365-2850.2009.01444.x

[34] Rosenblatt, L. (1978). The Reader, The Text And The Poem: The Transactional Theory of The Literary Work. Carbondale, IL: Southern Illinois University Press.

[35] Ruey, S. (2009). A Case Study of Constructivist Instructional Strategies for Adult Online Learning. British Journal of Educational Technology, 41(5), 706-720. http://dx.doi.org/10.1111/j.1467-8535.2009.00965.x

[36] Rushby, N., \& Surry, D. (2016). The Wiley Handbook of Learning Technology (1st ed.), p. 67. West Sussex: John Wiley \& Sons.

[37] Short, D. \& Fitzsimmons, S. (2007). Challenges and Solutions to Acquiring Language and Academic Literacy For Adolescent English Language Learners. Alliance for Excellent Education: Carnegie Corporation of New York. Retrieved from (https://www.carnegie.org/media/filer_public/bd/d8/bdd80ac7fb48-4b97-b082df8c49320acb/ccny_report_2007_double.pdf

[38] Spivak, G. (2010). “Can the Subaltern Speak?” In, Can the Subaltern Speak? Reflections on the History of an Idea. Rosalind Morris (ed.) Pp. 21-78. Retrieved from https://dadadocot.com/2012/10/10/spivakgayatrichakravorty-2010-can-the-subaltern-speak/

[39] Strauss, A. \& Corbin, J. (1990). Basics of Qualitative Research: Grounded Theory Procedures and Techniques. Newbury Park, CA: Sage Publications. Types of Transactions. (n.d.). Zeepedia.com [Online Database]. Retrieved from http://www.zeepedia.com/read.php?types_of_transactions_complementary _transactions_crossed_transactions_ulterior_transactions_human_resource_development $\& \mathrm{~b}=32 \& \mathrm{c}=11 \mathrm{x}$

[40] Uden, L., Wang, L., CorchadoRodríguez, J., Yang, H., \& Ting, I. (2014). The $8^{\text {th } I n t e r n a t i o n a l ~ C o n f e r e n c e ~}$ on Knowledge Management in Organizations (1st ed.), p. 112. Dordrecht: Springer Netherlands.

[41] Venuti, L. (2000). The Translation Studies Reader, Advisory editor: Mona Baker. London and New York: Routledge.

\section{AUTHORS' BIOGRAPHY}

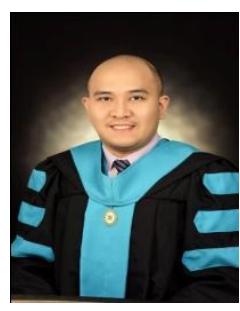

Dr. Reid Allen S. Ugsang finished his Master of Arts in Education in English Studies and Instruction as Cum Laude at Roosevelt College Foundation, Inc. He earned his Doctor of Education in Literature and Language Education from the Far Eastern University.

In his years of teaching, he has served as a subject coordinator, school paper adviser and professorial lecturer at the National Christian Life College (NCLC); resource 
speaker in campus journalism trainings and teachers development programs of National Christian Life College-Maranatha Christian Academy School System. At present, he is the principal of NCLC-High School Department.

He has participated in the following international seminars and workshops: ASEAN-India Student Exchange Programme; Global Startup Youth; YSEALI Generation: Startup Weekend ASEAN; 5 Global Forum on Research and Innovation for Health; ASEAN Impact Challenge; 5th ASEAN Future Leaders Summit; and presented his research in the 3rd International Conference on Language Literature and Cultural Studies (3rd ICLLCS).

Citation: Dr. Reid Allen S. Ugsang. "Interface of the Reader with the Text: From Individual to Group Transactions for Meaning" International Journal on Studies in English Language and Literature (IJSELL), vol 6, no.8, August 2018, pp. 39-49. doi:http://dx.doi.org/10.20431/2347-3134.0608005.

Copyright: () 2018 Authors. This is an open-access article distributed under the terms of the Creative Commons Attribution License, which permits unrestricted use, distribution, and reproduction in any medium, provided the original author and source are credited. 